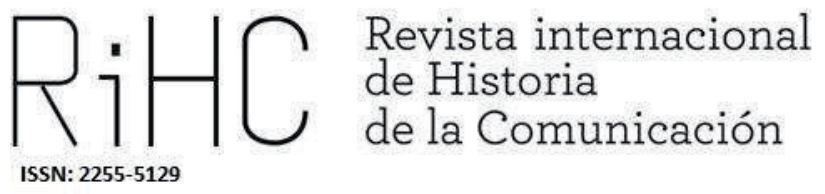

\title{
ORGANIZACIÓN Y CONTROL DE LAS CARRERAS DE POSTAS DEL PARAGUAY COMO ENTRAMADO DEL ESTADO NACIONAL ENTRE 1843 Y 1856
}

Organization and control of the post-house races from Paraguay as a framework of national Estate between 1843 and 1856

DOI: http://dx.doi.org/10.12795/RiCH.2021.i16.15

Recibido: 8-1-2021

Aceptado: 11-4-2021

Publicado: 31-6-2021

Jorge García Riart

Universidad Católica de Asunción, Paraguay

Centro de Investigaciones de Historia Social del Paraguay

jordiriart@yahoo.com

ORCID (D) 0000-0001-9728-3702 
Resumen: La organización y el control de las carreras de postas en el Paraguay, como medio de comunicación, entre 1843 y 1856, constituyó un factor importante para la consolidación de Estado nacional. Pocos estudios sociales incorporan la categoría de los correos postales como elemento de formación del nacionalismo. En este sentido, este trabajo es inédito al proponer el entramado de las postas como factor constituyente de la identidad nacional. Esta red de comunicación, compuesta por más de dos centenares de paradas oficiales, cuyos protagonistas fueron los maestros de postas y el contenido principal la orden oficial, contribuyó, en tiempo del nacionalismo lopista, también a moldear un sentido de territorio-nación y de conciencia social.

Palabras clave: Carreras de postas, Estado nacional, identidad nacional, maestros de postas, Paraguay.

\begin{abstract}
The organization and control of the post house races in Paraguay, as a means of communication, between 1843 and 1856, constituted an important factor for the consolidation of the national Estate. Few social studies incorporate the category of postal mail as an element of formation of nationalism. In this sense, this work is unprecedented in proposing the network of posts as a constituent factor of national identity. This communication network, made up of more than two hundred official stops, whose protagonists were the postmasters and the main content the official order, contributed, in the time of Lopista nationalism, to shape a sense of territory-nation and social conscience.
\end{abstract}

Keywords: Post-house races, national estate, national identity, postmasters, Paraguay.

\title{
Introducción
}

Hay autores que señalan la importancia de ciertos medios de comunicación, como el periódico, para la creación de conciencia nacional. El impacto de la prensa sobre la formación de opinión pública merece y mereció el interés de muchos estudios sociopolíticos. Otros canales de comunicación como la televisión y la radio son y fueron estudiados también como factores de la formación de cognición social.

Además de los medios que hemos citado, que han evolucionado considerablemente, existieron otros sistemas tradicionales concebidos para el necesario intercambio de información y/o de mercancía. En esta línea, el correo terrestre es la expresión emblemática de un tipo de transporte y reparto de correspondencia entre dos puntos lejanos entre sí.

Además de las expresiones del correo en la antigüedad, en Persia, Grecia o Roma, entre las poblaciones de la antigua América corrió el intercambio de mensajes por medio del chasqui o chasque, como se conoció a una persona que actuaba como corredor entre 
un lugar y otro. La colonización española tradujo el sustantivo de origen quechua al castellano peninsular postillón, que era el hombrecillo que hacía la carrera de posta en posta.

Así, las carreras de postas fueron un canal de comunicación implementado en América que evolucionó de rudimentarios usos y servicios a un sistema integrado y complejo de casas de postas o paradas bajo la regencia de los llamados maestros de postas, lo cual permitió unir pueblos y ciudades de provincias coloniales, primero, y de naciones independientes, luego. Las Reformas Borbónicas, que comenzaron en 1764 e incidieron lógicamente en las colonias americanas, sentaron las bases sobre el cual, más tarde, se constituirían los correos nacionales sobre la forma de nuevos Estados nacionales.

En este contexto, nos interesa reconstruir los itinerarios de las distintas carreras de postas del Paraguay (canales), reconocer a sus protagonistas (actores) e identificar sus contenidos (mensajes) como elementos componentes de un medio de comunicación que bajo control del Estado constituiría un importante entramado de consolidación del Estado nacional entre 1843 y 1856. La intencionalidad gubernamental debería estar explícita en las declaraciones de Gobierno, sea estas circulares, nombramientos o mensajes.

\section{Estado del arte}

Según Benedict Anderson (1993), algunas de las causas de la formación del nacionalismo son el acceso a las lenguas escritas particulares, la independencia de las ideas con respecto al absolutismo y la expansión de la prensa o del periódico papel. Estos elementos coinciden claramente con el surgimiento de muchas identidades latinoamericanas como noción diferencial de otras como la europea. Quizás Anderson olvida que los mapas, su diseño, impresión y divulgación, en el siglo XVI fueron también fundamentales para tener una visión periférica o de "aldea global" como se esforzó en explicar Marshal McLuhan (1998). Como vemos, Anderson y McLuhan se interesaron en el impacto de la imprenta de Gutenberg en la conformación de una noción de territorio, de identidad o de nación.

La siguiente descripción de dos expertos contemporáneos en evolución de la conciencia, James Burke y Robert Ornstein, resume acabadamente la fórmula propuesta de los teóricos citados en el párrafo anterior: “(...) la imprenta difundió el poder desde el antiguo centro papal hacia la periferia de los Estado-nación. Separó así a la gente mediante las fronteras de esos nuevos Estados, fomentando un sentimiento de 
separatismo nacional, conforme la actividad comercial iba haciéndose más fácil de regular y gestionar con ayuda de pasaportes impresos, salvoconductos, comunicados y todo tipo de documentos oficiales. Y como la imprenta alentaba la regulación del comercio, las economías de las nuevas naciones-Estado comenzaron a crecer y a desarrollar sus rasgos distintivos" (Burke y Ornstein, 1995: 159).

A pesar de todo, John Thompson llamó la atención acerca de que muchos teóricos sociales no se hayan preocupado de los medios de comunicación social en el desarrollo de las sociedades modernas. Anterior a la industria mediática, la sensación del pasado y/o de la distancia -siguiendo a Thompson- dependían fundamentalmente de los medios de comunicación (Thompson, 1998: 15).

En este sentido, queremos añadir a la teoría un elemento histórico que puede explicar complementariamente el nacimiento de la conciencia nacional: nos referimos al correo postal, como medio de comunicación.

Un paradigmático caso de las "poderosas" correspondencias que relativizan el orden instituido y plantean una noción de cambio encontramos en las "Cartas Persas" de Montesquieu a través de cuya obra satirizó a las autoridades del Absolutismo (Burke y Ornstein, 1995: 185). No fue casual el título. El Gran Correo de Ciro de Persia (s. VI. a.C.) implementó un sistema de relevo de caballos y de paradas que es considerado representativo en las historias de las comunicaciones sociales.

¿Por qué los persas alcanzaron esa perfección? Básicamente para controlar las fuentes de noticias que traían los mercaderes. Sobre este hecho, Manuel Vázquez Montalbán postula que la comunicación siempre va unida a la existencia del cambio de mercancía. Agrega: "los sistemas de correo y la comunicación ligada a la necesidad de cambio fueron los primeros instrumentos de comunicación internacional” (Vázquez Montalbán, 1997: 15).

Siguiendo a Vázquez Montalbán, sobre toda posibilidad de comunicación siempre actuaron dos elementos: el control estructural o monopolio estatal $y$, consecuentemente, el control legal o establecimiento de normas (1997: 17). Los citados condicionantes se explican mejor con estas palabras:

El control de la comunicación social se ha aplicado desde siempre a dar una intencionalidad al comunicado coincidente con los intereses del emisor para imponérselos al receptor. Los historiadores de la propaganda suelen esforzarse en distinguirla de información, como si pudiera concebirse una información sin intencionalidad persuasora cuando hay desigualdad evidente en la posición histórica que ocupan el emisor y el receptor (Vázquez Montalbán, 1997:18). 
En el ámbito local no encontramos estudios previos serios que conjuguen el entramado de las postas con la formación de la identidad nacional. En este sentido, nuestra investigación permanece inédita. Sin embargo, los pocos trabajos originales producidos anteriormente sobre las estafetas del Paraguay señalan el fuerte carácter oficial que imprimieron los gobiernos (coloniales y nacionales) sobre el control de la red de correspondencia.

Walter Bose (1940), en "Los Orígenes del Correo en el Paraguay 1769-1811"; Alfredo Seiferheld (1975), en "Filatelia, correos y sellos paraguayos"; Alfredo Viola (1983), en "Correos del Paraguay durante el gobierno del dictador Francia" y Juan Bautista Rivarola (2008) en "La Contabilidad colonial y las Cajas Reales de Hacienda" coinciden en la importancia de organizar el correo como factor de conexión del Paraguay colonial, primero, y del Paraguay independiente, después, con el mundo.

Desde la perspectiva marxista, la apertura desatada bajo la influencia política de Carlos Antonio López -bajo cuyo gobierno colocaremos la reconstrucción de los itinerarios de postas- es parte de la dictadura de la burguesía nacional. Oscar Creydt, en "Formación Histórica de la Nación Paraguaya" sostiene que el Estado Lopista fue "la principal fuente de acumulación de capital y su función fue colocar al Paraguay en la vanguardia entre los países latinoamericanos" (Credyt, 2010: 100).

Justo Pastor Benítez, en "Formación Social del Pueblo Paraguayo", contradice la tesis de Credyt: "El régimen de producción puede ser fundamental, pero no es factor único en la organización social" (Benítez, 1955: 129). Reconoce, empero, la "férrea voluntad del déspota" para interpretar la raíz nacional del pueblo (Benítez, 1995: 136). Justo Pastor insinúa que expresiones espontáneas de opinión popular, en idioma propio como el guaraní y en espacios abiertos de intercambio como la plaza-guazu (plaza grande) sentaron las bases de la identidad nacional (Benítez, 1995: 136). Günter Kahle estudia el idioma guaraní y su trascendencia en la formación de la conciencia nacional paraguaya en "Orígenes y fundamentos" específicamente bajo la Dictadura de Francia (Kahle, 1992: 97).

El estudio de "La integración nacional del Paraguay (1780-1850)" de Ricardo Pavetti (2008) coloca, para conocimiento y profundización de investigaciones ulteriores, elementos sociohistóricos y elementos político-institucionales, incluso elementos eclesiales y económicos. Pero, en este y otros trabajos de manufactura local, se nota la carencia de interés en aportar como categoría de estudio la influencia de los medios de comunicación en la formación de la conciencia nacional.

Si bien, hay estudios sobre el impacto de la primigenia prensa oficial surgida en tiempos de Carlos Antonio López denominada "El Paraguayo Independiente", cuya misión era 
conseguir el reconocimiento de la independencia del Paraguay, no hay publicaciones que aborden el fenómeno de la comunicación en la creación de la identidad nacional.

Aníbal Orué Pozzo reconoce que hay pocos estudios de comunicación sobre el significado del periodismo en el Paraguay. Los abordajes generales provienen de la historia política e institucional del país y, por ello interpretan, por ejemplo, la aparición de la prensa local desde la perspectiva de las instituciones políticas (Orué Pozzo, 2007: 19). Precisamente, el periodismo que surge en 1845 durante el gobierno de Carlos Antonio López, a criterio de Orué Pozzo, se corresponde con las necesidades políticas del naciente Estado paraguayo (Orué Pozzo, 2007: 20).

Aquí es -desde nuestra perspectiva- donde cabe colocar, además del periódico como medio de comunicación influyente en la noción de nación, entre 1843 y 1856, el papel de las carreras de postas como canal de comunicación estatal de relevancia para la conformación de una idea de territorio y de nación. No hay autores que hayan arriesgado esta interpretación hasta ahora.

\section{Metodología}

Para el desarrollo de la investigación exploramos documentos primarios del Archivo Nacional de Asunción -en adelante ANA- como son recibos de postas, pasaportes, nombramientos y decretos oficiales que proceden de distintas secciones, principalmente de la Sección Historia -en adelante SH- así como también de la Sección Nueva Encuadernación -en adelante NE-. Estas fuentes son fundamentales para hacer una reconstrucción de los itinerarios o de las carreras de postas en el Paraguay a mediados del siglo XIX.

Algunas de estas fuentes primarias son muy directas. Indican la intencionalidad de la autoridad de turno de compilar los itinerarios de postas y la responsabilidad de los maestros de postas "con respecto al cargo". De la lectura de otros folios, debieron reconstruirse los caminos a partir de la interpretación caligráfica.

A más de 170 años de la organización de estas postas, en su gran mayoría las construcciones físicas no quedan en pie pero sí el rastro de lo que fueron ya que los nombres quedaron grabados en compañías, barrios o pueblos de la actualidad. Tampoco hay rastros de aquellos antiguos senderos. Esa es una dificultad que tuvimos que salvar en la composición de los trayectos o carreras de postas. 
Para la contextualización temporal de la organización de las postas en el Paraguay, utilizamos producción secundaria, primordialmente local aunque no muy exhaustiva, tales como "Los Orígenes del Correo en el Paraguay 1769-1811" de Walter Bose (1940) y "Filatelia, correos y sellos paraguayos" de Alfredo Seiferheld (1975). Con documentos del ANA verificamos la autenticación de algunos hechos.

\section{Resultados}

\subsection{Antecedentes del correo en el Paraguay}

Cuando en 1764, el Estado borbónico inició la reforma de los correos ultramarinos entre España y América, además de impulsar la estatización o el control de los canales de comunicación terrestres, cimentó el surgimiento de particularidades en las redes de conexión de mensajería de las provincias coloniales sobre las cuales, luego, se formaron estados nacionales, como el caso del Paraguay que veremos a continuación.

Las carreras de postas del Paraguay, principalmente la llamada "Carrera del Sur", que comunicaba Asunción con Buenos Aires, tienen sus orígenes remotos en las postas de las Misiones jesuíticas. Tras la expulsión de los sacerdotes de la Compañía de Jesús, en 1767, se incorporaron las primigenias postas misioneras a la Real Renta de Correos, lo cual coincide con las Reformas normativas introducidas por la dinastía de los Borbones.

En 1769, Domingo Basavilbaso _organizador del correo de Buenos Aires_y Carlos Morphi_gobernador del Paraguay (1766-1772)- acordaron el establecimiento de estafetas y correos entre ambas provincias (Bosé, 1971: 90). Desde la Metrópolis a Asunción el itinerario fue conocido como Carrera del Paraguay y se consolidó entre 1772 y 1774 (Seiferheld, 1975: 23).

En 1791, se organizó un nuevo itinerario postal entre la Capital Asunción y la Villa Real de Concepción, hacia el norte, bajo los esfuerzos del comandante Juan Bautista Rivarola (Rivarola, 2008: 382), que más tarde se transformó en la "Carrera de Costa Arriba", atravesando pasos, estancias y pueblos.

La Administración de Correos de Villarrica fue controlada desde Buenos Aires desde su creación en 1796. Julián Legal y Córdova fue su primer administrador (ANA, Sección Historia, vol. 186, n.3). 
Desde 1802, el gobernador de la Provincia del Paraguay, Lázaro de Rivera (1794-1806), fue también subdelegado de la Real Renta de Correos (Seiferheld, 1975: 26). En Buenas Aires, los correos eran dirigidos por Antonio Romero de Tejada.

El proceso de independencia del Paraguay de la Corona española se inició en 1811 con ciertas interrupciones del correo con el Río de la Plata. Los patriotas sustituyeron al administrador particular de correos de Asunción devenido en administrador general del Paraguay, Bernardo Jovellanos, por Ramón Azuaga. A pesar de las primeras restricciones en la comunicación con Buenos Aires, se entendió que era conveniente abrir los canales con la Metrópolis (Seiferheld, 1975: 26-27).

A principios de 1815, bajo el gobierno del Gaspar Rodríguez de Francia, Miguel Decoud reemplazó a Azuaga (Seiferheld, 1975: 27). En 1832, aún bajo la Dictadura de Francia, fue designado Juan Manuel Álvarez como administrador general de correos, estafetas y postas de la República del Paraguay (Seiferheld, 1975: 28). Bajo este gobierno se dio prioridad a las comunicaciones oficiales (Verón y Biedermann, 2004: 43).

A la muerte de Francia, sucedió un gobierno consular integrado por Mariano Roque Alonso y Carlos Antonio López (1841-1844), que prestó atención a la relación de postas en vigencia. El llamado Segundo Consulado comenzó la reestructuración del servicio de postas (Verón y Biedermann, 2004: 42). Un par de años después, bajo la presidencia unipersonal de López (1844-1862), fue designado administrador general interino de Correos, Hermenegildo Quiñones (Seiferheld, 1979: 29-30), en sustitución de José Manuel Álvarez.

\subsection{Consolidación de la red de postas nacional}

Carlos Antonio López se convirtió en el primer presidente constitucional del Paraguay en 1844, tras la aprobación de la Ley que establece la Administración Política de la República del Paraguay. En realidad, ejerció el poder compartido con Mariano Roque Alonso desde 1841 tras una corta inestabilidad política que surgió a la muerte del Dictador Francia en 1840.

Bajo el Segundo Consulado -como se señaló- hubo voluntad de reorganizar las carreras de postas. Los inventarios solicitados con respecto a la extensión, cantidad de postas y maestros de postas existentes en las líneas del correo terrestre resaltan en el ANA principalmente en este periodo. Este empeño es sintomático de las primeras acciones llevadas a cabo por el Gobierno de López-Alonso: reorganizó las autoridades de campaña, reparó y abrió caminos y convocó a un Congreso para la jura de la Independencia (Benítez, 1949: 23). 
Como parte de la renovación de autoridades en el interior de la República emprendida por el Segundo Consulado las circulares emitidas por el Administrador General de Correos seguía esta forma: "esprese a continuación su nombre y apellido, el nombre del lugar de la posta a su cargo, la distancia de leguas que hay desde allí á la siguiente posta inmediata, y el tiempo que tiene su servicio en el ministerio de maestro de posta, procediendo de este modo desde la primera hasta la última, desde donde se devolverá á esta Administración...." (ANA, SH, vol. 259, n. 12[3]).

Las primeras comunicaciones firmadas por López-Alonso son muy evidentes de la utilidad de restablecer las carreras de postas para reorganizar la hacienda. "Ynformara Ud. por la posta en continuacn. de esta orden si ha mejorado la hacienda del Estado en disposicion q. pueda moverse de allí a Concepcion alguna partida considerable de ganado..." (ANA, NE, vol. 1944/ Colección José Doroteo Barrios, Sección Presidente Carlos Antonio López, vol. 2, p. 555).

O esta otra que explica el control de las postas para evitar costos excesivos en la comunicación oficial: "Es estraño q no hayan Ilegado a esa comandancia las órdenes generales que el Govno. mandó circular pa. que las postas no sean gravadas con auxilios estraños a su institucion..." (ANA, SH, vol. 257, n. 6).

O el denodado interés en convertir las postas en un servicio público: "Tambien me informara un lugar que pueda destinarse para un puesto donde puedan recaudarse los diezmos de cuatropea de esa jurisdicción, y llevarse de las estancias del Estado algunas yeguas y caballos pa. facilitar en adelante los ausilios de las Postas y otros servicios públicos" (ANA, NE, vol. 1357/ Colección José Doroteo Barrios, Sección Presidente Carlos Antonio López, vol. 5, p. 1447).

Se dice que la Ley de la Administración Política del país es la primera Constitución dictada por un Congreso Soberano. Sea lo que fuere, representó un avance jurídico frente al Reglamento de Gobierno de 1813 (Benítez, 1949: 34). Estableció, al menos en el papel, la división de los poderes del Estado: Legislativo, Ejecutivo y Judicial. El Título VII determinó las atribuciones del Presidente de la República, entre las cuales, decía que "todos los ramos de obras públicas, camino, postas, correos, establecimientos de educación primaria y científicos costeados por los fondos de Nación, todos Jos objetos y ramos de hacienda y policía son de la suprema inspección y resorte del Presidente de la República" (Seiferheld, 1979: 25).

Siguiendo esta política nacionalista, López, el primer presidente constitucional, realizó nuevos nombramientos de maestros de postas e inventario de las carreras de posta. En 1845, fue nombrado administrador del Correo de Villarrica, Francisco Trifón Mareque, esta vez, en subordinación de la Administración General de Correos (ANA, SH, vol. 259, 
n. 13, f. 19.) El mismo año, el Presidente López promulgó un reglamento y formulario de partes (ff. 20-22).

En 1854, se elaboró un reglamento o régimen que debía seguir el intercambio de cartas, impresos o bultos, que a razón estableció los costos que debían pagarse por cada tipo de elemento según su peso o procedencia. Las tarifas establecidas favorecieron a las correspondencias venidas desde puntos limítrofes, zonas militares ocupadas o de puntos que tienen movimiento comercial. Entonces, el administrador general de Correos fue Francisco Javier Acuña (ANA, SH, vol. 326, n. 5).

Seiferheld interpreta que el primer periodo presidencial de C. A. López se caracterizó por un "incremento progresista", de adelanto en la administración del correo postal que "trajeron al país un sistema de comunicación bien definido, con postas establecidas en puntos cercanos y lejanos entre sí". Consciente de que "el buen manejo de las postas reportaba a la nación", López satisfecho de la obra informó a los Representantes de la Nación que entre los muchos socorros y gratificaciones "no fueron olvidadas los empleados en las postas que hacen un servicio incesante a la Patria" (Seiferheld, 1975: 30-31).

En las siguientes hojas, presentamos la descripción más exhaustiva posible de los itinerarios de postas en todas las latitudes del territorio paraguayo que hemos encontrado en el ANA.

\subsection{Carrera de Costa Arriba}

La Carrera de Costa Arriba se dibuja sobre la margen izquierda del río Paraguay hacia el norte. Su línea responde estratégicamente con la custodia de la soberanía sobre el territorio y las aguas que conectaban con el Brasil. Incluía 22 paradas que se extendía por 46 leguas y media, a juzgar por el conteo que realizó el administrador general de Correos, Juan Manuel de Álvarez a mediados de 1843 (ANA, SH, vol. 259, n. 13[2]), el equivalente a $224 \mathrm{~km}$ aproximadamente.

La línea partía de la Capital obviamente y se dirigía hasta la Villa de Concepción atravesando los siguientes puntos: Ybyray (hoy un barrio de Asunción, Trinidad), Tapúa, Peñón, Salado (estos tres en jurisdicción de la actual Limpio), Paso Guazú (sobre el río Piribebuy), Ycuarusú, (río), Pirapó, (río) Manduvirá (río), Aramburu (Capiipobó), Altos (pueblo de naturales), Barranquera de Yobi, Ypitá, Guardia de Ybirayú, Rosario, San Pedro, Itacué, Arroyo, Piripucú, Taquarita, Taquara y Belén.

De las nomenclaturas de las postas, sabemos que el recorrido pasaba por accidentes geográficos (ríos y arroyos) así como por puestos de estancias y guardias o piquetes 
militares. Se destacan en la ruta poblaciones ya establecidas como Villa del Rosario, Villa de San Pedro, Belén y Villa de Concepción.

Como se nota en la Tabla 1, la relación de postas de la Carrera de Costa Arriba indica un total de 22 postas, aunque en el original indique 21; probablemente el Administrador se saltó una posta en el cálculo.

Quizás por la distancia entre una posta y otra o para acortar distancia, en los sucesivos años se reorganizaron las postas de esta Carrera, se agregaron o salieron unas y otras en la medida en que se nombraban nuevos maestros de postas. Por ejemplo, en 1845, en otra relación de recibos de postas, figura la Posta de Limpio, a cargo de Pedro Telmo González (entre Peñón y Salado). La Posta de Altos y la Posta de Itacué no están en la lista y sin embargo se incluye la Posta de la Barranquera de Uruguaitá donde fungía de maestro de posta el capataz de José Tomás García, Ilamado Julián Ibarrola (ANA, Sección Civil y Judicial, vol. 2053, n. 9, f. 7). A principios de ese año, el maestro de posta de Tapúa, Francisco de Sales González fue sustituido por Luis Insfrán, maestro de posta de Surubiy (ANA, SH, vol. 277, n. 3, f. 106).

Entre los maestros de postas, mayoritariamente masculinos, encontramos el nombre de una mujer, Josefa Acosta Bernabé, correspondiente a la Posta de Taquara.

A juzgar por los recibos de posta, siguiendo esta línea, un pliego dirigido por el Presidente de la República para la Comandancia de Concepción salió a la 1 de la tarde del 25 de febrero de 1845 y llegó a destino a las 3 de la tarde del 27 de febrero de 1845; una demora de 50 horas equivalente a dos días y dos horas (ANA, SH, vol. 275, n. 4, ff. 98-100v.).

Oficialmente la Carrera terminaba en Concepción, pero a necesidad de comunicación con otros puntos más remotos, la transmisión de mensajes cerrados podía llegar más al norte hasta los fortines ubicados sobre el río Apa. Precisamente, en 1843, se establecieron 4 nuevos fortines, a saber: Apatuyá, Gavilancué, Yvyruguá y Apadesgracia (ANA, SH, vol. 256, n. 12).

\begin{tabular}{|c|c|c|}
\hline$\#$ & Posta & Maestro de Posta \\
\hline 1 & Ybyray & José Mariano Xara \\
\hline 2 & Tapúa & Francisco de Sales González \\
\hline 3 & Peñón & José Gregorio del Cazal \\
\hline 4 & Salado & Francisco Gauna \\
\hline 5 & Paso Guazú (Piribebuy) & José Pablo Ruydias \\
\hline
\end{tabular}




$\begin{array}{lll}6 & \text { Ycuarusú } & \text { José María Trigo } \\ 7 & \text { Pirapó } & \text { Lorenzo José Osuna } \\ 8 & \text { Manduvirá } & \text { José Joaquín Burgos } \\ 9 & \text { Aramburu (Capiipobó) } & \text { José Norberto Gomes } \\ 10 & \begin{array}{l}\text { Altos (pueblo de } \\ \text { naturales) }\end{array} & \text { José Pasqual Paqua } \\ 11 & \text { Barranquera de Yobi } & \text { Julián Ibarrola, capataz } \\ 12 & \text { Ypitá } & \text { José Domingo Velázquez } \\ 13 & \text { Guardia de Ybirayú } & \text { Francisco González } \\ 14 & \text { Rosario } & \text { Francisco Antonio Caballero, interino } \\ 15 & \text { San Pedro } & \text { José Dolores Roxas } \\ 16 & \text { Itacué } & \text { Ramón Serapio Hurtado } \\ 17 & \text { Arroyo } & \text { Juan Manuel Morales } \\ 18 & \text { Piripucú } & \text { Juan Bautista Haedo } \\ 19 & \text { Taquarita } & \text { José Tomás García } \\ 20 & \text { Taquara } & \text { Josefa Acosta } \\ 21 & \text { Belén } & \text { José Vicente Quandú, secret. Cabildo } \\ 22 & \text { Concepción } & \text { José Mariano Xara, adm. interino } \\ & & \end{array}$

Elaboración propia a partir de ANA, SH, vol. 259, n. 13(2)

\subsection{Carrera de Costa Abajo}

La Carrera de Costa Abajo, como su nombre lo dice, se dirigía aguas abajo siguiendo la línea del río Paraguay hasta llegar con territorios correspondiente a la Provincia de Corrientes. Su trayecto incluía 27 postas, contando desde Ysaty (hoy un barrio de Asunción) hasta Paso de Patria, el hito más austral del país. La extensión total era de 63 leguas, aproximadamente $302 \mathrm{~km}$.

Con la ayuda de las copias de recibo de la circular del Administrador de Correos de 1843 (ANA, SH, vol. 259, n. 12), sabemos que en la unión de cada extremo de la vía postal estaban las siguientes postas: San Antonio, Abay (Villeta 1a), Cumbaryty (Villeta), Surubiy (Zanjita 1), Zanjita, Paso del Poraí, Saladillo 1, Saladillo 2, Villa Alta (propiedad de los Urbieta), Zanjita Norte, Zanjita Sur, Isla Pindó, Paso Pe (Villa Franca), Peguahó, Echevarría, Isla Potrero (río Tiviquari 2ª), Paso del (río) Tiviquari, Yacaré, Mburicada, 
Montuoso, Paso del río Ñeembucú, Pilar 1ạ. norte, Pilar 2ạ. sur (Boquerón), Humaitá y Curupayty.

Nótese en la Tabla 2, que de la segunda posta de Villeta se bifurcaba (hijuela) el recorrido hasta su unión con Carapeguá, que correspondía a la Carrera del Sur.

Al igual que otros trayectos de correos, pueden observarse mojones geográficos que denotan nombres de pasos de ríos y arroyos (como Paso del Ñeembucú y Paso del Tebicuary), aguadas, colinas (Villa Alta) y depresiones (zanjas) del terreno, así como localidades concretas tales como Villeta y Pilar.

Entre tantos nombres de varones, se distingue el de María Prudencia Recalde, maestra de posta de Villa Alta, jurisdicción de Saladillo en la propiedad de los Urbieta, con cuyo apellido también fue conocida la parada.

Con respecto a la dilación de la correspondencia entre Asunción y Paso de Patria, nuestros cálculos con las copias de recibo en mano, señalan 4 días. Por ejemplo, el mensaje del Administrador de Correos para costa abajo salió de origen el 26 de junio de 1843 y llegó a destino el 30 de junio de 1843 (no específica horas).

\begin{tabular}{lll}
\multicolumn{3}{c}{ Tabla 2 Carrera de Costa Abajo, 1843.} \\
1 & Posta & Maestro de Posta \\
2 & Ysaty (Lambaré) & Melchor Fernández \\
3 & San Antonio & Juan de Dios Cabrera \\
4 & Cumbaryty (Villeta) & Pedro Pablo Aguilar \\
H & Villeta 2a $\rightarrow$ Carapeguá & Agustín Osorio \\
5 & Surubiy (Zanjita 1) & Andrés Vallejos \\
6 & Zanjita & José Félix Oviedo \\
7 & Paso del Poraí & Casimiro Mancuello \\
8 & Villa Saladillo 1 & José Fermín Paredes \\
9 & Villa de Saladillo 2 & Francisco Binardi \\
10 & Villa Alta o Urbieta & María Prudencia Recalde \\
11 & Zanjita Norte & Ananías de Goiburú \\
12 & Zanjita Sur & José Pastor Gómez \\
13 & Isla Pindó & Juan José Gómez \\
\hline
\end{tabular}




$\begin{array}{lll}14 & \text { Paso Pe (Villa Franca) } & \text { Francisco Domingo Gauto } \\ 15 & \text { Peguahó } & \text { Agustín Benítez } \\ 16 & \text { Chavarría } & \text { Paulo Genes } \\ 17 & \text { Isla Potrero (Tiviquari 2â) } & \text { Simón Flores } \\ 18 & \text { Paso del Tiviquari } & \text { José Evaristo Vega } \\ 19 & \text { Yacaré } & \text { Juan de Rosa Ayala } \\ 20 & \text { Mburicao } & \text { José Claudio Duré } \\ 21 & \text { Montuoso } & \text { Juan Esteban Vel } \\ 21 & \text { Paso de Ñeembucú } & \text { Juan de la Cruz Aguilar } \\ 22 & \text { Pilar 1a. Norte } & \text { Eusebio Avalos } \\ 23 & \text { Pilar 2a. Sur (Boquerón) } & \text { Juan de la Cruz Rivero } \\ 25 & \text { Humaitá (Jomaita) } & \text { José Domingo Hermosa } \\ 26 & \text { Curupayty } & \text { Juan de la Cruz Gómez } \\ 27 & \text { Paso de Patria } & \text { Félix Hermosa }\end{array}$

$\mathrm{H}$ : hijuela o ramal è: dirección

Elaboración propia a partir de ANA, SH, vol. 259, n. 12(2) | ANA, SH, vol. 259, n. 12

\subsection{Carrera del Sur}

La Carrera del Sur es la más antigua del Paraguay. Tiene sus orígenes en las misiones jesuíticas. Ahora, incorporadas a la soberanía del país, requerían ser fortalecidas. Estratégicamente atravesaba transversalmente la región occidental.

A la luz de la Circular emitida por el Administrador de Correos con respecto a los cargos de maestros de postas, en 1843 (ANA, SH, vol. 259, n. 12 [3]), la Carrera del Sur contó con 42 postas desde Ysaty hasta la Villa de la Encarnación; la más extensa del país a juzgar por la cantidad de paradas. En cuanto a distancia, la suma de las leguas de separación entre cada posta da como resultado 70 y media leguas, aproximadamente $350 \mathrm{~km}$.

El itinerario de la vía del sur comenzaba en la Posta de Ysaty -que también conectaba con la Carrera de Costa Abajo- así como su continuación, la Posta de San Antonio. Luego seguía por los siguientes puestos: Ypané, Guarnipitán, Arroyo del Ytá, Piraguazú, Estancia Añagatí (Itá), Carapeguá, Aguay, Mbatachí, Tabapy (Estancia del Estado), Tobatinguá, Arroyo Tacuary (Quiindy), Quiindy, Caapucú 1aㅡ, Caapucú 2aa․,Apichapá (Caapucú), Yaguary (Caapucú) y río Tibicuary (Caapucú). 
En la otra banda del río Tebicuary estaba el Paso de Santa María (actual Villa Florida), desde donde el correo proseguía por antiguas postas de extracto jesuítico, ahora al servicio de la República. Esas postas fueron: Lima (San Ignacio), San Mauricio (Santa María), San Pedro (Santa María), San Antonio (Santa María), Estancia Loreto (Santa María), Santa María, Parabé (Santa María), Santa Rosa, San Patricio, Ñacutí, San Ramón (Santiago), San Luis, Paso de San Damián, San Rafael (San Cosme), Costa del Aguapey (San Cosme), San Antonio (San Cosme), San Isidro (San Cosme), Del Carmen (antes Tuparay), San Lorenzo (Del Carmen), San Juan (Del Carmen), Arroyo Jú (Yhú) y Encarnación.

En el trayecto puede notarse una rica toponimia alusiva a arroyos y ríos como arroyo Itá y río Tebicuary. También, se destacan los nombres de estancias como la de Añagatí y la de Tavapy del Estado (actualmente San Roque González de Santa Cruz).

Por el territorio de Misiones, los puestos de correos tomaron generalmente los nombres que dejaron los jesuitas, y debido a la tradición, muchas de esas postas estuvieron administradas aún en tiempos de Carlos Antonio López por indígenas, como Xara de San Luis, Arambayú de San Lorenzo y Cayaré de San Juan.

De la lista de maestros de postas (Tabla 3), podemos reconocer el nombre de María Francisca Chaparro, en correspondencia con la Posta del Paso de Santa María quien, según su declaración escrita, llevaba el servicio a su costa hace 37 años.

La correspondencia oficial corría bastante rápida por esta vía (en un día, señalan algunas fuentes), sin embargo, en la ocasión analizada, la orden del Administrador General de Correos salió de Asunción el 27 de junio de 1843 y recién llegó a Encarnación el 16 de julio de 1843, lo cual implicó una demora un promedio de 2,4 días por posta. 


\begin{tabular}{|c|c|c|}
\hline$\#$ & Posta & Maestro de posta \\
\hline 1 & Ysaty & Melchor Fernández \\
\hline 2 & San Antonio & Juan de Dios Cabrera \\
\hline 3 & Ypané & Sebastián Vallejos \\
\hline 4 & Guarnipitán & Roque Paniagua \\
\hline 5 & Ao. del Ytá & Agustín Osorio \\
\hline 6 & Piraguazú & Juan E. Alemán \\
\hline 7 & Estancia Añagatí (Itá) & Valentín Guayú \\
\hline 8 & Carapeguá & Rafael Benítez \\
\hline 9 & Aguay & José Fortunato Rolón \\
\hline 10 & Mbatachí & Eugenio Ávalos \\
\hline 11 & Tabapy (Estancia del Estado) & Roque González \\
\hline 12 & Tobatinguá & Pablo Giménez \\
\hline 13 & Arroyo Tacuary (Quiindy) & Matías González \\
\hline 14 & Quiindy & Juan Ascensio González \\
\hline 15 & Caapucú 1aㅗ & Juan Vicente Lovera \\
\hline 16 & Caapucú 2ạ & Domingo Esteban Leguizamón \\
\hline 17 & Apichapá (Caapucú) & Francisco Amarilla \\
\hline 18 & Yaguary (Caapucú) & Mariano Marcelino Noguera \\
\hline 19 & Tibicuary (Caapucú) & José Domingo Cavañas \\
\hline 20 & Paso de Santa María & María Francisca Chaparro \\
\hline 21 & Lima (San Ignacio) & Felix Palacios \\
\hline 22 & San Mauricio (Santa María) & Santiago Silva \\
\hline 23 & San Pedro (Santa María) & Gregorio Chaves \\
\hline 24 & San Antonio (Santa María) & Juan Crisóstomo Villaverde \\
\hline 25 & Estancia Loreto (Santa María) & Francisco Piriyú, capataz \\
\hline 26 & Santa María & Lázaro Centurión, adm. del pueblo \\
\hline 27 & Parabé (Santa María) & Bernardino Colmán \\
\hline 28 & Santa Rosa & Julián Bogado \\
\hline
\end{tabular}




$\begin{array}{lll}29 & \text { San Patricio } & \text { Juan Manuel Ribas } \\ 30 & \text { Nacutí } & \text { Thomas Antonio Bernal } \\ 31 & \text { San Ramón (Santiago) } & \text { José Bernardo Galiano } \\ 32 & \text { San Luis } & \text { José Ignacio Xara } \\ 33 & \text { Paso de San Damián } & \text { Santiago Chaparro } \\ 34 & \text { San Rafael (San Cosme) } & \text { Agustín Barboza } \\ 35 & \text { Costa del Aguapey (San } & \text { José Mariano Centurión } \\ & \text { Cosme) } & \\ 36 & \text { San Antonio (San Cosme) } & \text { Manuel José Pacheco } \\ 37 & \text { San Isidro (San Cosme) } & \text { José Carmelo Ramírez } \\ 38 & \text { Del Carmen (antes Tuparay) } & \text { Nicolás Tab...capataz } \\ 39 & \text { San Lorenzo (Del Carmen) } & \text { Juan de Dios Arambayù } \\ 40 & \text { San Juan (Del Carmen) } & \text { Pedro Cayaré } \\ 41 & \text { Ao. Jú (Yhú) } & \text { guardia de soldados } \\ 42 & \text { Encarnación } & \text { Juan Pablo Benítez, comandante }\end{array}$

Elaboración propia a partir de ANA, SH, vol. 259, n. 12 (3)

\subsection{Línea del Paraná}

En 1849, bajo el gobierno de Carlos Antonio López se organizó una vía de postas al norte y al sur del río Paraná, en este último caso en territorio que aún pertenecía al Paraguay. Con fecha 4 de julio, el Presidente decretó que en la brevedad posible se arreglasen las corridas y las postas desde la Comandancia de la Villa de la Encarnación hasta la Tranquera de Loreto (actual Ituzaingó, Argentina), por un lado, y hasta el río Uruguay, por otro lado (ANA, SH, vol. 286, n. 16)

Dos escuadrones de soldados debían atender los pasos de Candelaria, Campichuelo y de San José, a cargo del capitán de Caballería Vicente Anselmo Gómez y el alférez Vicente Franco, respectivamente.

También resolvió poner un piquete militar en San Carlos y otro en Bareiro para controlar los pasos de Garrucho, San Lucas y Santa María La Mayor. En Santo Tomás debía haberse montado una posta en comunicación con la de San Carlos, así como en Itaimbé para mantener enlace con la Tranquera de Loreto. 
Si bien la orden tuvo carácter provisorio, finalmente López, en 1849, decidió reforzar la Tranquera de Loreto como frontera del país antes las hostilidades de los correntinos (ANA, SH, vol. 256, n. 17).

\subsection{Línea del Centro}

La llamada Línea del Centro conectaba Asunción con la orilla del río Tebicuary, atravesando 41 paradas en su recorrido. Se puede decir, era un canal de correspondencia que unía viejos asentamientos urbanos nacidos bajo la Colonia con antigua misiones franciscanas. De hecho, su trayecto en parte, coincidía con el camino de la explotación de la yerba mate.

Del otro lado de la última posta, estaba Bobí, un punto nodal o de conexión entre una carrera y otra. Su ordenamiento data recién de 1856 a instancias del nuevo administrador general de correos, Francisco Xavier Acuña.

De hecho, debido a la observancia de la red que practicó el Administrador, la carrera cruzaba una serie de localidades y accidentes geográficos que citamos: Asunción, Recoleta Sur, San Lorenzo, Capiatá, Cañada Toledo, Cañada Aldana, Itá, Ñanduá,

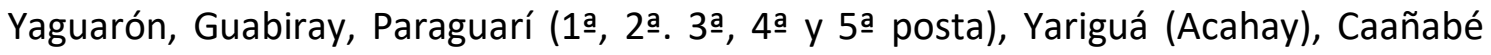
(Acahay), Arroyo Caballero (Acahay), Caballero Punta (Ybycuí), Arroyo Insaurralde (Ybycuí), Ybycui, Tacuarí (Ybycui), Potrero Buemé (Ybycui), Arroyo Ybycui (Mbuyapey), Mbuyapey, Paso de Tebicuarimi (lado Mbuyapey), Paso de Tebicuarimi (lado Caazapá), Caazapá (dos postas), Caracaray, Santa Ana, Santa Teresa, Puesto Naranjo, De Jesús María, Pirapó (última de Caazapá), Yuty, Santa Bárbara (Yuty) y (río) Tivicuari (ANA, SH, vol. 320, n. 24, ff. 283-290v.).

En la Tabla 4 se puede apreciar la comprensión de varias postas en una misma jurisdicción. Así, el departamento que más postas tuvo fue Caazapá con 8 paradas, le siguió Paraguarí e Ybycuí con 5 postas, Acahay y Mbuyapey con 4 y Asunción y Yuty con 3. ¿Por qué hubo divisiones políticas con más postas? No encontramos una respuesta certera al respecto, pero suponemos que la explicación no se corresponde necesariamente con la extensión de los partidos sino con la división patrimonial, es decir con la cantidad de propiedades particulares que atravesaba la línea; por ello los nombres de los maestros de postas son diferentes.

Lamentablemente, la solicitud del Administrador de Correos para ordenar la vía del centro no estuvo acompañada de datos sobre distancia entre una parada y otra; solo podemos confirmar la demora de la nota entre la primera posta de Asunción y la última de Yuty en las orillas del Tebicuary: salió el 13 de agosto y llegó a destino el 13 de 
septiembre, un promedio de 1,3 días de retención en cada posta durante un mes. Tampoco la numeración de postas, que cada maestro de posta apuntó en su recibo, no es exacta: hay un orden salteado o equivocado.

En este último caso, la única mujer identificada como maestra de posta en la Línea del Centro, María Benigna Guerreros, parece equivocarse en el conteo de su posta: en principio le correspondía el número 31, pero en el manuscrito asentó "vigésima octava". No sabemos por qué.

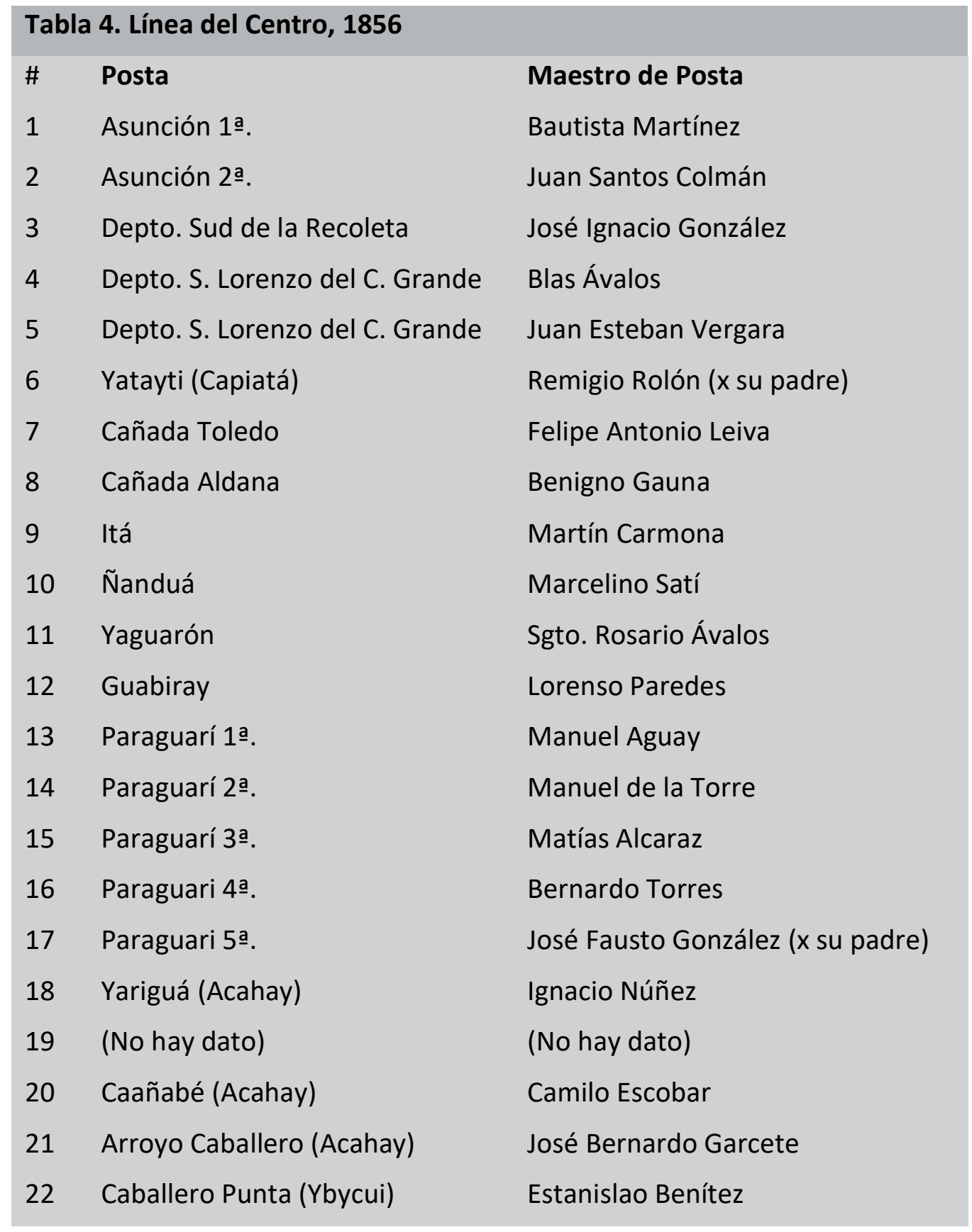




\begin{tabular}{lll}
23 & Arroyo Insaurralde (Ybycui) & José David Román \\
24 & Ybycui & Juan Bautista Zarza \\
25 & Tacuarí (Ybycui) & José Ramón Bogado \\
26 & Potrero Buemé (Ybycui) & Sgto. José Ramón Cavallero \\
27 & Arroyo Ybycui (Mbuyapey) & Antonio Jiménez \\
28 & Mbuyapey & Bartolomé Jiménez \\
29 & Paso de Tebicuarimi (Mbuyapey) & Angelo Duarte \\
30 & Paso de Tebicuarimi (Caazapá) & Lisardo Bareiro \\
$* 28$ & Caazapá & María Benigna Guerreros \\
31 & Caazapá & Juan Andrés Farina \\
32 & Caracaray & Ramón Benítez \\
33 & Santa Ana & Telésforo Ortiz \\
$* 34$ & Santa Teresa & Domingo Villalba \\
$* 34$ & Puesto Naranjo & Juan Francisco Báez \\
$* 34$ & De Jesús María & José Mariano Mereles \\
37 & Pirapó (última de Caazapá) & Juan Quiterio Centurión \\
38 & Yuty & Agustín Gauto \\
39 & Santa Bárbara (Yuty) & Luis Acosta \\
40 & (Río) Tivicuari $\rightarrow$ Bobí & Marceliano Larramendia \\
\hline & &
\end{tabular}

*: La numeración viene de los recibos originales con evidencia de un error involuntario en el conteo (?) è: dirección o hijuela

\subsection{Línea del Ñeembucú}

Hacia el oeste de San Ignacio están los esteros del Ñeembucú, que en época de lluvias era intransitable, incluso en la actualidad. Sobre ese pantano se trazó una vía de sucesivas paradas que podemos denominar la Línea del Ñeembucú. No era un camino habitual, pero el Administrador de Correos, en 1856, tomo la determinación de ordenarlos para el mejor cumplimiento de sus funciones.

Esta carrera se formó con 29 postas ubicadas en distintos puntos de la complicada travesía que incluía ríos, arroyos, aguadas, lagunas y nacientes, lo cual nos hace suponer la necesidad de establecer una cantidad extraordinaria de postas en una sola jurisdicción para salvar las dificultades del camino. Así, podemos observar, que la comprensión de 
San Ignacio contuvo 7 postas y la de Desmochado, 8 postas. La jurisdicción de Laureles agrupó 5 postas y la de Yataity, 4 postas que sumadas con las del distrito de Laureles la convierte en la jurisdicción más grande.

Los pasos y las postas del camino, desde Capilla San Ignacio hasta Villa del Pilar, fueron en este orden: San Dionicio, Isla Guazú, Taturuguay, Curupicay, Caranay (todos de San Ignacio); Rodeito, Gavilán, Mercado, Caarogüe, Laureles (todos de Laureles); Ñeembucumi (2 postas), Yataity (también alcance de Laureles, según los recibos; dos estaciones llamadas Manantiales y otras seis más de la demarcación de Desmochados; dos más nombradas Curupayty y, finalmente, el Paso del Ñeembucú (ANA, SH, vol. 320, n. 24 , ff. 15-25).

Para tener una idea de la distancia temporal de la Línea del Ñeembucú, no física, nos valemos de las fechas al pie del recibo firmado por cada maestro de posta. La circular del Administrador de Correos pasó por la de San Ignacio el 22 de octubre de 1856 y llegó al Paso del Ñeembucú, en la cercanía de Pilar, el 8 noviembre de 1856; demoró 17 días, un promedio de 1,7 días por cada parada.

\begin{tabular}{lll} 
Tabla 5. Línea del Ñeembucú, 1856 \\
$\#$ & Jurisdicción de Posta & Maestro de Posta \\
1 & Manuel Rosario Céspedes, mayordomo \\
2 & Miguel Martínez \\
3 & Juan Antonio Chávez \\
4 & San Ignacio & Pedro Galeano \\
5 & Bautista González \\
6 & Francisco Velázquez \\
7 & Manuel Antonio Mesa \\
8 & Eduardo Osuna \\
9 & Gregorio Gavilán \\
10 & Laureles & Gregorio Mercado \\
11 & & Pedro Antonio Viveros \\
12 & & Inocencio Maidana \\
13 & Ñeembucumí & Julián Candia \\
14 & & José Toribio Espínola \\
15 & Yataity (Laureles) & Juan Crisóstomo Arévalos \\
\hline
\end{tabular}




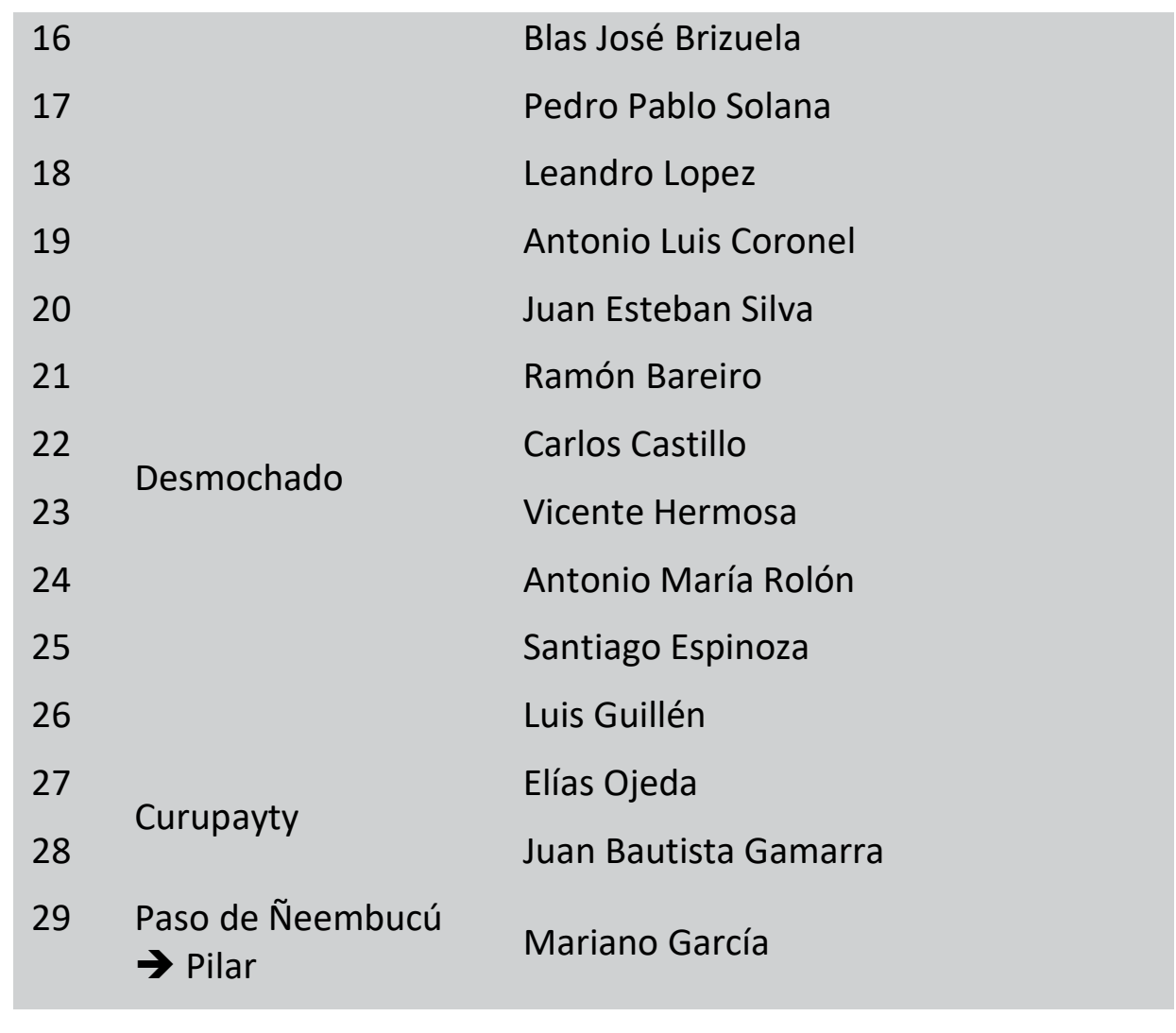

é: dirección o hijuela

Elaboración propia a partir de ANA, SH, vol. 320, n.24.

\subsection{Carrera de Villarrica}

Como hemos señalado, la Carrera de Villarrica es un caso curioso de significar en la red postal del Paraguay decimonónico. Su origen no se ajusta a la organización de correos de la Administración de Asunción, sino que es totalmente independiente. Su dependencia inicial es la Real Renta de Correos de Buenos Aires. Funcionó como una pista paralela a la Carrera del Sur que dependió de la Administración Principal de Asunción.

Sin embargo, los documentos de ANA señalan la intención del Gobierno nacionalista de López de incorporarlo al sistema de postas para el tráfico de correspondencia oficial principalmente. Un informe de la Administración de Correos de Villarrica, en 1844, explicaba que los pasos contaban con suficientes canoas y las postas con suficientes caballos para el servicio (ANA, SH, vol. 403, n.1, f. 136).

No pudimos reconstruir el itinerario exacto solo a partir de fuentes primarias. Pero sí reconocimos que en 1847 persistieron alrededor de Villarrica las siguientes postas: Yacamí (arroyo), Itaibú, Yvaroty, Tupizá, Yacaguazú (río), Tebicuary (río), Santa Ana 
(estancia), entre otras; también hacia el norte había postas en Caaguazú, Ajos y San Joaquín.

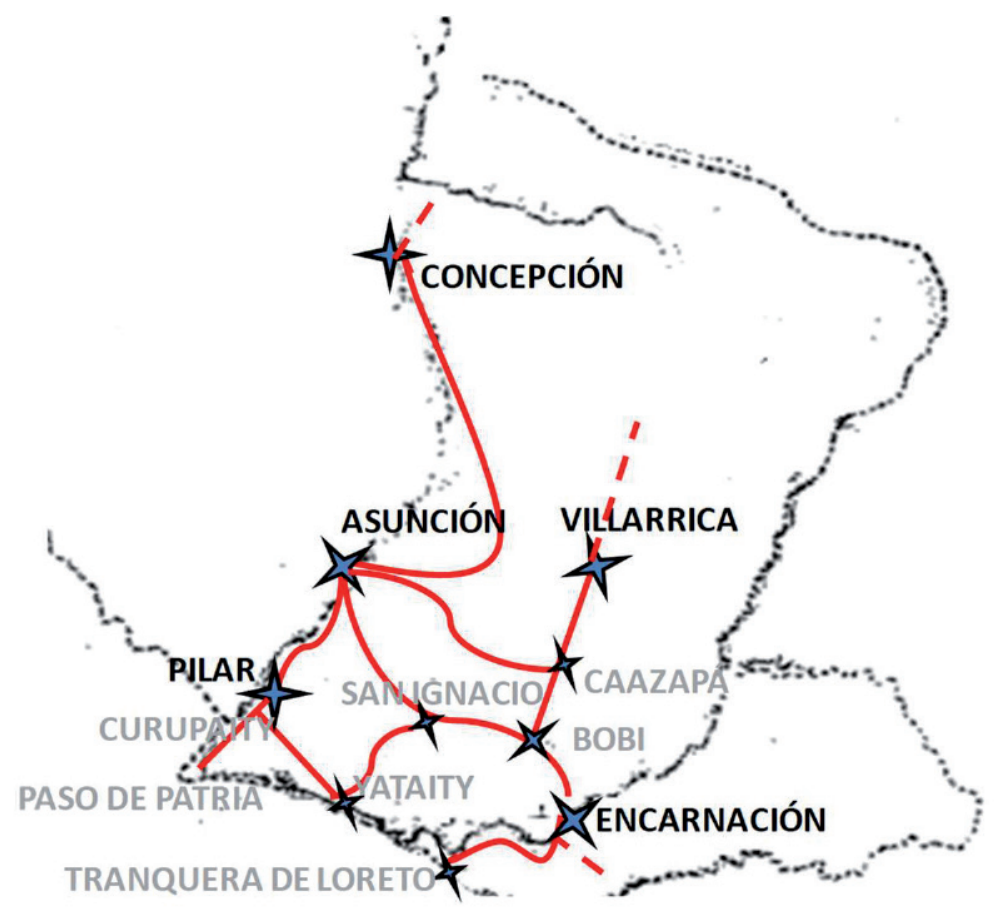

Figura 1. Mapa de las carreras de postas del Paraguay, 1843-1856. Elaboración propia a partir de un mapa del Paraguay antes de finalizar la Guerra Grande (1870) y documentos del ANA.

\section{Conclusión}

Durante el mandato de Carlos Antonio López se organizaron nuevos recorridos postales como la "Carrera de Costa Arriba", la "Carrera de Costa Abajo", la "Línea del Centro", incluso la "Línea del Paraná" en la banda sur del río, como un entramado de estructuración del Estado paraguayo. Por ello, los maestros de postas, nombrados por el propio Presidente, se convirtieron en funcionarios públicos aunque a su propia costa; en compensación fueron librados del servicio militar o del pago de otros impuestos.

La Figura 1 corresponde a los itinerarios de postas del Paraguay antes del final de la Guerra Grande (1870) que trajo como consecuencia la enajenación de importante superficie territorial a favor de Brasil y Argentina, vencedores de la Contienda. Las distintas líneas que cruzan gran parte del país (excepto el Chaco, extremo occidental del mapa) configuran, al mismo tiempo, las sendas del control estatal, no solo sobre las comunicaciones sino también sobre el territorio. 
Léase en esta clave la importancia de marcar postas al sur del Río Paraná, en suelo reivindicado como propio, o de enlazar la Capital con los principales puertos de entrada y salida del país (Pilar, Encarnación, Concepción). Esto indica, en cierta forma, que la red postal del Paraguay Lopista se tejió en conjugación con los intereses mercantiles genuinos como nación y como tuberías de proyección periférica. En este sentido, las interpretaciones de autores marxistas, referidos en apartados anteriores, tiene sentido.

En esta lógica, no es casual la incorporación de la Administración de Correos de Villarrica, subordinada, antes al Buenos Aires colonial, ahora, a la Administración General de Correos del Paraguay independiente.

En este entramado comunicacional, compuesta por más de dos centenares de paradas oficiales, las carreras o las líneas fueron los canales, los maestros de postas los actores subalternos y la orden oficial el mensaje principal que corría por el medio. Todo este complejo sistema de comunicación contribuyó, en tiempo del nacionalismo lopista, a moldear un sentido de territorio-nación y de conciencia social, en definitiva, la base de un nuevo Estado nacional.

Desde el punto de vista comunicacional, nos parece importante recuperar el estudio sobre las comunicaciones de postas, como el caso del Paraguay, como factor constituyente del Estado nacional. Este estudio cubre un vacío intelectual sobre el papel de las postas de correos en la conformación de la noción o idea de nación. Sin embargo, sobre el mismo carácter oficial de las postas (su control y su organización) se encuentran los antecedentes de la conformación del Estado nacional paraguayo entre 1843 y 1856.

Anderson, Mc Luhan, Thompson, Vázquez, entre otros, resaltan el factor mediático en la formación de territorio, identidad o nación. El control de los medios por parte del Estado, históricamente, han coincidido con los intereses del emisor. En esta línea, cabe ubicar una nueva interpretación sobre las carreras oficiales de postas en el Paraguay decimonónico. Es extraño que autores locales no hayan advertido este factor cuando tradicionalmente los estudios se han centrado en el papel de la prensa.

Sin embargo, Seiferheld propuso escuetamente la posibilidad de comprender la organización y el control de las carreras de postas en el Paraguay de Carlos Antonio López. La frase "el buen manejo de las postas reportaba a la nación" es explícita de la intencionalidad gubernamental de consolidar el Estado nacional en la mitad del siglo XIX.

Solo dibujando aquellos caminos podemos comprender la relevancia de la red postal en la conformación del Estado paraguayo y por ende de la identidad nacional. En ese diseño sobresale la nomenclatura guaraní que distinguió accidentes geográficos (arroyos, ríos, 
aguadas) se respetó. Hasta ahora perduran en el imaginario popular las denominaciones locales que otrora fueron pasos o postas.

En cierta medida, la red funcionó con eficiencia. La correspondencia corrió generalmente en un tiempo prudencial de ida y de vuelta, sin más obstáculos que pudieron ser vencidos por la voluntad del postillón y la fidelidad del maestro de posta al servicio público. Los postillones siempre fueron jóvenes, los maestros de postas pudieron ser guardias, capataces, indígenas, mujeres, siempre que la posta recayera en un piquete, en una estancia, en un pueblo de indios o en una posada, respectivamente.

\section{Referencias Bibliográficas}

BENÍTEZ, J. P. (1949). Carlos Antonio López, estructuración del Estado paraguayo. Buenos Aires, Ayacucho.

BENÍTEZ, J. P. (1995): Formación Social del Pueblo Paraguayo, Buenos Aires, AméricaSapucai.

BOSÉ, W. (1940): Los Orígenes del Correo en el Paraguay 1769-1811. Edición Especial.

BURKE, J. y ORNSTEIN, R. (1995): Del hacha al chip. Cómo la tecnología cambia nuestras vidas, Barcelona, Planeta Divulgación.

CREYDT, O. (2010): Formación Histórica de la Nación Paraguaya, Asunción, Servilibro.

KAHLE, G. (2005): Orígenes y Fundamentos de la Conciencia Nacional Paraguaya, Asunción, Instituto Cultural Paraguayo Alemán.

MCLUHAN, M. (1998): La galaxia Gutenberg, Barcelona, Círculo de Lectores.

ORUÉ POZZO, A. (2007): Periodismo en Paraguay. Estudios e interpretaciones, Asunción, Arandurá.

PAVETTI, R. (2008): La integración nacional del Paraguay (1780-1850). Biblioteca de Estudios Paraguayos, vol. 69, Asunción, CEADUC.

RIVAROLA, J. B. (2008): La Contabilidad Colonial y las Cajas Reales de Hacienda, Asunción, Intercontinental.

SEIFERHELD, A. (1975): Filatelia, correos y sellos paraguayos. Buenos Aires, Mundo Filatélico. 
THOMPSON, J. (1998). Los media y la modernidad. Una teoría de los medios de comunicación, Barcelona, Paidós Ibérica.

VÁZQUEZ MONTALBÁN, M. (1997): Historia y comunicación social, Barcelona, Crítica.

VERÓN, L. y BIEDERMANN, E. (2004): Las Tintas del Tintero. Reseña y anecdotario de la prensa escrita en el Paraguay, Asunción, Cerneco.

VIOLA, A. (1983): "Correos del Paraguay durante el Gobierno del Dictador Francia”, en Cuadernos Republicanos, n. 21, pp. 73-94.

\section{Documentales del Archivo Nacional de Asunción}

Sección Civil y Judicial, vol. 2053, n. 9, Expediente de informe y desocupación del puesto en la Barranquera de Uruguayta...

Sección Historia, vol. 256, n. 12, Decreto que establece cuatro fortines en las fronteras del Río Apa.

Sección Historia, vol. 256, n. 17, Orden al Comandante de la frontera con Corrientes sobre disposiciones en el campamento.

Sección Historia, vol. 257, n. 6, Órdenes y Resoluciones de los Cónsules de la República

Sección Historia, vol. 259, n. 13, Títulos de Maestros de Postas.

Sección Historia, vol. 259, n. 13[2], Circular del Administrador General de Correos a los maestros de postas de la vía de la Villa Encarnación, respecto al cargo.

Sección Historia, vol. 259, n. 12 [3], Circular del Administrador General de Correos a los maestros de postas de Costa Abajo, respecto al cargo.

Sección Historia, vol. 275, n. 4, Recibo firmado por las Postas de Correos para dos pliegos urgentes enviados a la Comandancia de Villa de Concepción.

Sección Historia, vol. 277, n. 3, Correspondencias de Asunción.

Sección Historia, vol. 286, n. 16, Decreto organizando el Servicio de Postas entre Encarnación y la Comandancia de Loreto.

Sección Historia, vol. 320, n. 24, Recibos de postas de correos sobre copias de una determinación del Administrador General de Correos.

Sección Historia, vol. 326, n. 5, Administración de Correo. Reglamento sobre carta. 
Sección Historia, vol. 403, n.1, Correspondencias del pueblo de Villarrica del Espíritu Santo.

Colección José Doroteo Bareiro - ANA

Sección Presidente Carlos Antonio Lopez, vol. 2 - (1842 - 1844)

Sección Presidente Carlos Antonio Lopez, vol. 5 - (1847 - 1848) 